Jurnal Pemberdayaan: Publikasi Hasil Pengabdian kepada Masyarakat

Vol. 3, No. 2, Agustus 2019, Hal. 173-178

ISSN: 2580-2569; e-ISSN: 2656-0542

DOI: https://doi.org/10.12928/jp.v3i2.917

\title{
Pemberdayaan masyarakat dalam upaya pengembangan literasi pada anak-anak di Dusun Jaten Triharjo Pandak Bantul
}

\author{
Muchsin Maulana ${ }^{1}$, Eko Prasetyo $^{2}$, \\ Universitas Ahmad Dahlan, jalan Prof Dr Soepomo SH Yogyakarta ${ }^{1}$ \\ Transip Rent Jogja, Jl.Muria No 9A, Banguntapan, Bantul ${ }^{2}$ \\ Email: muchsin.maulana@ikm.uad.ac.id
}

\begin{abstract}
ABSTRAK
Masih rendahnya minat membaca anak-anak juga dapat mempengaruhi minatnya dalam menulis. Tentunya hal ini juga akan mempengaruhi perkembangan dan pengetahuan seorang anak di tingkat pendidikannya. Oleh karena itu kegiatan yang berkaitan dengan literasi sangatlah penting untuk mengoptimalkan kemampuan membaca dan menulis seorag anak. Permasalahan yang didapat adalah sulitnya remaja mengakses taman baca yang ada di pedukuhan Jaten. Program ini bertujuan untuk meningkatkan kemampuan literasi pada anak seperti membaca dan menulis di dusun Jaten Triharjo Pandak Bantul Metode yang digunakan dalam pengabdian ini adalah tanya jawab kepada anak-anak terkait pentingnya membaca dan menulis. Kemudian dilanjutkan dengan beberapa kegiatan seperti lomba membaca puisi, membaca pantun dan mendongeng. Anak-anak sangat antusias mengikuti beberapa lomba yang telah dilaksanakan. Kegemaran anak-anak dalam membaca dan menulis membuat taman bacaan yang telah didirikan di dusun Jaten sering dikunjungi
\end{abstract}

Kata kunci: Literasi, Membaca dan Menulis

\begin{abstract}
The low interest in reading children can also influence their interest in writing. This will also affect the development and knowledge of a child in their education. Therefore activities related to literacy are very important to optimize the ability to read and write as a child. This program aims to improve literacy skills in children such as reading and writing in Jaten hamlet Triharjo Pandak Bantul The method used in this service is a question and answer to children regarding the importance of reading and writing. Then followed by several activities such as reading of poetry competitions, reading of rhymes and storytelling. Children are very enthusiastic in participating in several competitions that have been held. The children's hobbies in reading and writing make reading parks in Jaten hamlet that have been established is visited
\end{abstract}

Keywords: Literacy, Reading and Writing

\section{PENDAHULUAN}

Budaya dalam membaca dan menulis di Indonesia masih sangatlah rendah. Hal ini dibuktikan berdasarkan data TIMSS dan PIRLS bahwa tingkat membaca untuk siswa kelas IV SD di Indonesia hanya mencapai skor 428. Skor tersebut masih di bawah rata-rata skor internasional yaitu 500. Hal tersebut menujukan bahwa kemampuan membaca anak-anak di Indonesia masih rendah dibandingkan negara lain. Maka dari itu diperlukan budaya literasi yang tidak hanya dilaksanakan di Sekolah namun juga dilingkungan tempat bermain dan berkumpul anak-anak (Mullis et al., 2012).

Sebelum adanya taman bacaan ini, masyarakat maupun anak-anak di dusun Jaten kesulitan untuk menuangkan minat membaca dan kesulitan mencari tempat untuk berdiskusi terkait materi Sekolah. Memberikan stimulasi pembelajaran pada anak harus sesuai dengan karakteristik anak, yaitu berorientasi pada kegiatan yang menyenangkan. Agar tercapainya 
kegiatan literasi yang menyenangkan diperlukan metode dan media yang baik karena kedua hal tersebut merupkan faktor penting untuk menjalankan literasi (Hapsari, Ruhaena and Pratisti, 2017).

Tujuan pengabdian ini untuk menyalurkan minat membaca anak-anak di Dusun Jaten, menjadikan pengabdian untuk menghidupkan kembali kegiaatan anak-anak di luar sekolah yang bermanfaat baik bagi masyarakat, anak-anak maupun Instansi terkait. Pada Pengandian ini digunakan metode dan media yang menarik agar anak-anak antusias untuk membaca dan menulis. Kegiatan tersebut diantaranya yaitu didirikannya taman bacaan, lomba membaca puisi, membuat pantun dan mendongeng. Taman bacaan didirikan di RT 02 Dusun Jaten, dimulai dari plangisasi hingga penomoran buku. Diharapkan dengan didirikan taman bacaan ini, anak-anak dapat meluangkan waktuya untuk membaca disela-sela waktu bermainnya.

\section{METODE}

Kegiatan pendirian taman bacaan dan gerakan gemar membaca dilaksanakan pada tanggal 28, 30 Januari dan 01 Februari 2019 di rumah kepala Dukuh Jateh. Metode pelaksanaan yang diterapkan dalam pendirian taman bacaan dan gerakan gemar membaca di mulai dengan metode persiapan, pendirian, dan pembimbingan. Metode persiapan dimulai dari pengumpulan buku yang didapatkan dari sumbangan dari pemerintah, sumbangan dari perpustakaan Daerah Istimewa Yogyakarta dan sumbangan dari mahasiswa KKN di Dusun Jaten. Selain itu juga dilakukan pelabelan pada setiap buku sesuai dengan jenisnya, kemudian dilakukan penyampulan buku. Metode pendirian dilakukan dengan menyerahkan buku-buku kepada kepala Rukun Tetangga yang bertanggung jawab atas taman bacaan tersebut, kemudian melakukan penataan buku dan mensosialisasikan administrasi taman bacaan kepada pemuda pemudi di Dusun Jaten yang bertugas sebagai pengelola. Metode pembimbingan dilakukan dengan mengajak anak-anak untuk melakukan kegiatan di taman bacaan seperti kegiatan bimbingan belajar sekaligus membaca buku.

\section{HASIL, PEMBAHASAN, DAN DAMPAK}

Pada saat pelaksanaan lomba anak-anak sangat antusias mengikutinya. Bahkan anakanak sudah berada di lokasi perlombaan sebelum lomba dimulai atau datang lebih cepat dari waktu yang ditentukan. Padahal jarak rumah mereka ke lokasi perlombaan tidaklah dekat, terutama jika ditempuh dengan jalan kaki. Lomba yang dilaksanakan yaitu lomba baca puisi, membuat pantun, dan mendongeng. Banyak anak-anak yang tidak mengikuti lomba tersebut namun tetap datang untuk meramaikan lomba literasi tersebut.

Pengumuman lomba diumumkan beberapa hari setelah pelaksanakannya lomba. Bagaimanapun aktivitas literasi merupakan salah satu aktivitas penting dalam hidup. Sebagian besar proses pendidikan bergantung pada kemampuan dan kesadaran literasi. Budaya literasi yang tertanam dalam diri generasi muda mempengaruhi tingkat keberhasilan baik di jenjang pendidikan maupun dalam kehidupan bermasyarakat (Suragangga, 2017). pemahaman mengenai Gerakan Literasi Sekolah yang terkait dengan pengertian Gerakan Literasi Sekolah yaitu program yang menyangkut pembiasaan membaca, berwawasan luas dan berkreasi. Adapun pemahaman yang terkait dengan tujuan Gerakan Literasi Sekolah yaitu meningkatkan minat baca, menambah pengetahuan, melatih berpikir kritis, berpendapat, dan memecahkan masalah (Hidayat, Basuki and Akbar, 2018). Persaingan global menjadi sebuah tantangan yang tercipta seiring perkembangan zaman. Tantangan tersebut dapat dijawab melalui penguasaan literasi dalam segala aspek kehidupan yang menjadi tulang punggung kemajuan peradaban bangsa. Tidak mungkin menjadi bangsa yang besar dan dapat bersaing dalam kancah internasional, apabila hanya mengandalkan budaya oral yang mewarnai pendidikan (Irianto and Febrianti, 2017). 


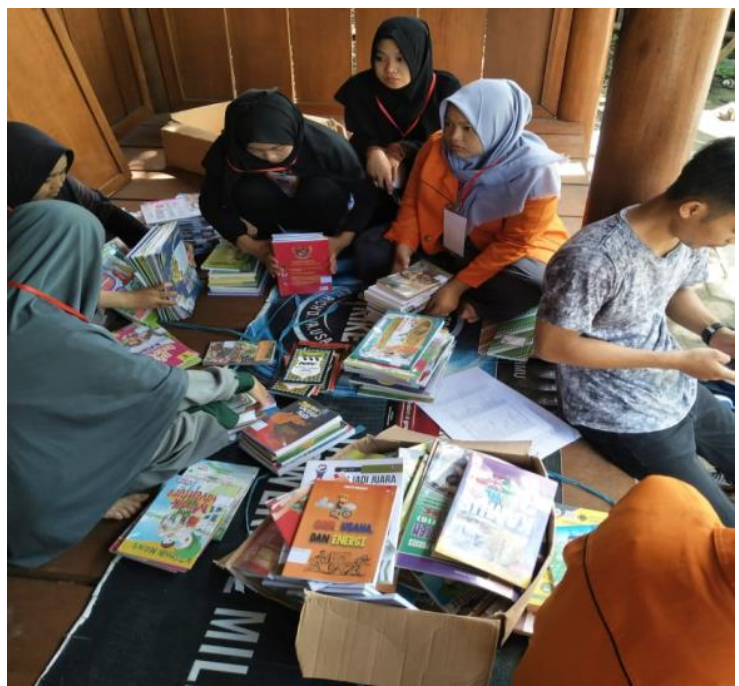

Gambar 1: Proses pelabelan buku oleh mahasiswa KKN UAD

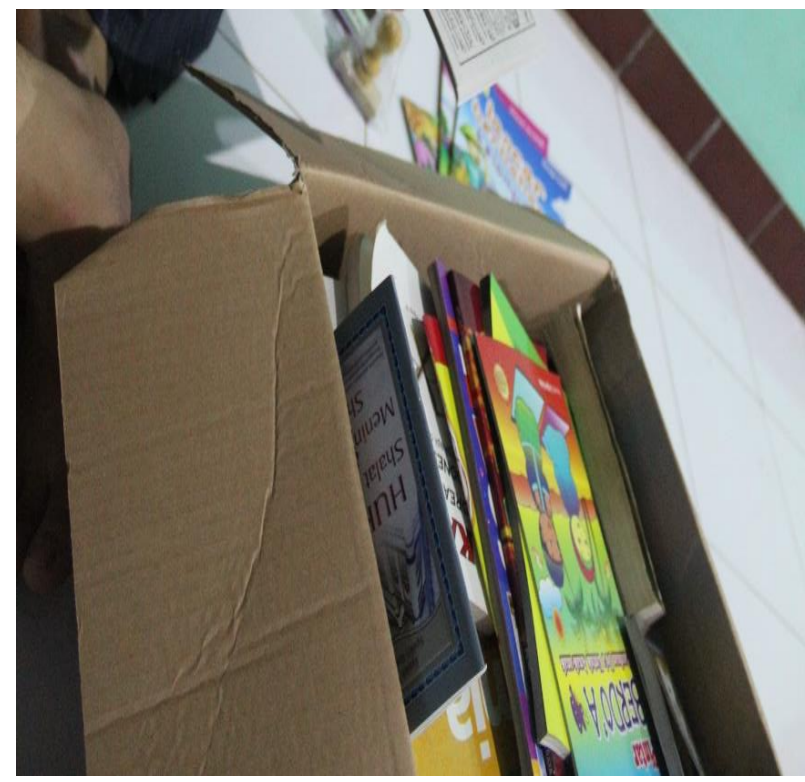

Gamabr 2: Buku hasil dari Sumbangan Perpustakaan daerah maupun sumbangan dari teman-teman KKN

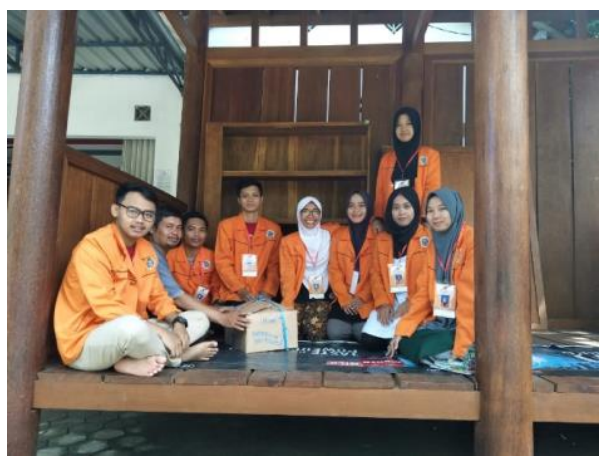

Gambar 3: Proses pelabelan selesai dan selanjutnya proses pendistribusian

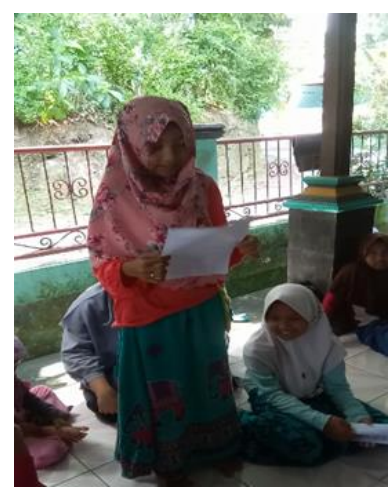

Gambar 4: Lomba membaca 
Sebelum adanya taman bacaan ini, anak-anak di dusun Jaten belum ada wadah atau tempat untuk menyalurkan minat membaca ataupun diskusi terkait materi maupun tugas sekolah. Selama pelaksanaan kegiatan mendirikan taman bacaan hingga lomba literasi, tidak ada kendala yang berarti. Anak-anak dusun Jaten sangat senang dengan adanya taman bacaan, mereka tertarik dengan buku-buku yang ada di taman bacaan tersebut. Pelaksanaan lomba membaca puisi, membuat pantun dan mendongeng juga disambut dengan antusias oleh anakanak.

\section{SIMPULAN}

Literasi pada anak-anak dapat dikembangkan dengan menggunakan metode dan media yang menarik. Salah satunya yaitu mendirikan taman bacaan dan melaksanakan berbagai lomba yang dapat mengasah kreatifitasnya dalam membaca dan menulis. Anak-anak sangat senang sekali saat tamaan bacaan telah didirikan, mereka juga sangat antusias saat mengikuti lomba-lomba tersebut.

\section{UCAPAN TERIMAKASIH}

Ucapan terima kasih, kami haturkan kepada masyarakat dusun Jaten Triharjo Pandak Bantul, yang telah berpartisipasi sehingga pengabdian masyarakat ini dapat terlaksana. Kami ucapkan Terima Kasih juga kepada Mahasiswa KKN IV B 1 UAD di Dusun Jaten Triharjo Bantul serta Mas Eko Prasetyo sebagai tim editor yang sudah menyempurnakan naskah ini.

\section{DAFTAR PUSTAKA}

Hapsari, W., Ruhaena, L. and Pratisti, W. D. (2017) 'Peningkatan Kemampuan Literasi Awal Anak Prasekolah Melalui Program Stimulasi', Jurnal Psikologi, 44(3), p. 177. doi: 10.22146/jpsi.16929.

Hidayat, M. ., Basuki, I. . and Akbar, S. (2018) 'Gerakan literasi Sekolah Dasar', Jurnal Pendidikan: Teori, Penelitian, dan Pengembangan, 3(6), pp. 810-817. Available at: http://journal.um.ac.id/index.php/jptpp/article/view/11213.

Irianto, P. O. and Febrianti, L. Y. (2017) 'Pentingnya penguasaan literasi bagi generasi muda dalam menghadapi MEA', The 1st Education and Language International Conference Proceedings, pp. 640-647. Available at: http://jurnal.unissula.ac.id/index.php/ELIC/article/view/1282.

Mullis, I. V. S. et al. (2012) PIRLS 2011 International Results in Reading, TIMSS \& PIRLS International Study Center. doi: 10.1097/01.tp.0000399132.51747.71.

Suragangga, I. M. N. (2017) 'Mendidik Lewat Literasi Untuk Pendidikan Berkualitas', Jurnal Penjaminan Mutu, 3(2), pp. 154-163. Available at: http://ejournal.ihdn.ac.id/index.php/JPM. 
